\title{
Giant Perianal Condyloma Successfully Treated with Podophyllin at 25\% in Solid Petrolatum
}

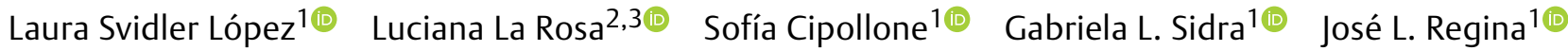 \\ Rita L. O. Pastore ${ }^{1(0)}$ Teresa Orcinoli ${ }^{4}$ Elizabeth A. Stier ${ }^{50}$
}

\footnotetext{
${ }^{1}$ Division of Surgery, Hospital Juan A. Fernández, Buenos Aires, Argentina

${ }^{2}$ Centro Privado de Cirugía y Coloproctología, Buenos Aires, Argentina

3 Department of Surgery, Centro de Educación Médica e

Investigaciones Clínicas, Buenos Aires, Argentina

${ }^{4}$ Division of Pharmacy, Hospital Juan A. Fernández, Buenos Aires, Argentina

${ }^{5}$ Department of Obstetrics and Gynecology, Boston University School of Medicine, Boston, Massachusetts, United States
}

J Coloproctol 2021;41(3):289-294.

\begin{abstract}
Address for correspondence Laura Svidler López, MD, División de Cirugía, Hospital Juan A. Fernández, Avenida Cerviño 3356, C1425, Buenos Aires, Argentina (e-mail: lausvidlerlopez@gmail.com).
\end{abstract}

\begin{abstract}
Keywords

- giant condiloma

- podophyllin

- topical treatment

- HPV

- immunosupression

Purpose Giant perianal condyloma (GPC) is a rare condition. The effective treatment is a multidisciplinary challenge; topical treatments are usually ineffective, and surgical resection has significant morbidity. Podophyllin at $25 \%$ in solid petrolatum (25\%PSP) can be an effective treatment option for GPC. The aim of the present study was to assess its response and tolerability.

Methods This retrospective, single-center case series evaluated the clinical response of 14 patients with GPC treated with 25\%PSP in a public hospital in Buenos Aires between December 2015 and December 2019. After obtaining a full history and performing a physical exam, the lesions were measured and photographed. Biopsies were performed to exclude malignancy, as well as exams to rule out pregnancy. Podophyllin at $25 \%$ in solid petrolatum was administered topically in cases of GPC and washed off by the patients at home after 4 hours. The patients underwent at least 4 weekly visits, which included interval history, photodocumentation of the lesions, and provider-applied 25\%PSP. The response rate was assessed by comparing measurements and the overall decrease in volume of the GPC based on photos from the first and last sessions. Adverse outcomes were noted.

Results In total, 10 men, 3 women, and 1 transgender woman with GPC unresponsive to prior treatments and a mean age of 34.5 years were included. A total of 12 patients were immunosuppressed. All the perianal lesions were circumferential and measured between $8 \mathrm{~cm}$ and $20 \mathrm{~cm}$. Overall, 7 patients had genital condyloma outside of the anus and perianus; the histology showed low-grade squamous
\end{abstract}

received

November 2, 2020

accepted after revision

March 22, 2021

published online

August 13, 2021
DOI https://doi.org/

10.1055/s-0041-1732329.

ISSN 2237-9363. (c) 2021. Sociedade Brasileira de Coloproctologia. All rights reserved.

This is an open access article published by Thieme under the terms of the Creative Commons Attribution-NonDerivative-NonCommercial-License, permitting copying and reproduction so long as the original work is given appropriate credit. Contents may not be used for commercial purposes, or adapted, remixed, transformed or built upon. (https://creativecommons.org/ licenses/by-nc-nd/4.0/)

Thieme Revinter Publicações Ltda., Rua do Matoso 170, Rio de Janeiro, RJ, CEP 20270-135, Brazil 
intraepithelial lesions in all cases. While on treatment, 7 patients reported dermatitis, and $71 \%$ of the patients had $\geq 75 \%$ reduction in lesion size.

Conclusions Podophyllin at $25 \%$ in solid petrolatum is an effective, well-tolerated topical treatment option for GPC.

\section{Introduction}

The effective treatment of giant perianal condyloma (GPC) is a multidisciplinary challenge: commercially-available topical treatments are generally ineffective, and surgical resection is associated with a risk of morbidity. Giant perianal condylomas are frequently associated with bleeding, pain, and malodorous discharge, and they interfere with hygiene, self-image and sexuality. ${ }^{1-3}$ Surgical excision of GPC is associated with risks of chronic pain, wound infection, incontinence, or anal stenosis, which could interfere with quality of life. ${ }^{4,5}$ Because of the potential perioperative and postoperative morbidities, effective non-surgical options would be very helpful.

Podophyllotoxin has significant antiviral and cytotoxic action, and is found in podophyllin, a resin extracted from the root of Podophyllum peltatum or Podophyllum emodi. In developed countries, solution compounds of podophyllin have been replaced by commercial formulations of its active principle, podophyllotoxin. In Argentina, podophyllin formulations are five times less costly than commerciallyavailable podophyllotoxin, and it is extracted from P. emodi, which contains $25 \%$ more podophyllotoxin than $P$. peltatum. $^{6-8}$

Although locally compounded podophyllin in alcohol solutions for the treatment of condyloma has fallen out of favor, ${ }^{8}$ we were inspired by the work of Brazilian coloproctologist Dr. Sidney Nadal, who successfully treated condyloma in people living with HIV (PLHIV) with P. emodi compounded in a petrolatum (commonly known as vaseline) base. ${ }^{9,10}$

In the present single-center case series study, we report our findings on the effectiveness and safety of $25 \%$ podophyllin in solid petrolatum (25\%PSP) to treat GPC.

\section{Methods}

We conducted a retrospective analysis of the clinical records of the patients from a public hospital in Buenos Aires with GPC measuring at least $8 \mathrm{~cm}$ (longest dimension) treated between December 2015 and December 2019. The present study was approved by the hospital's Ethics Committee (under no. 2586).

The patients were referred to our tertiary referral proctology service after failure of the topical treatment (trichloroacetic acid solution at $90 \%$, or imiquimod cream at $5 \%$ in other institutions.

Charts were reviewed for demographic and clinical data. Biopsies were taken from suspicious zones if present, or from the center and the margins of the lesion to exclude malignancy. Pregnancy was ruled out.
The hospital pharmacy compounded $25 \mathrm{~g}$ of $P$. emodi resin with $75 \mathrm{~g}$ of solid vaseline to make 25\%PSP. At each (weekly) treatment session, interval medical history with reports of side effects from the treatment was collected. Photographs of the GPC were taken with a ruler for calibration. Then 25\%PSP was applied by the provider to all the external lesions. Solid petrolatum was applied to the surrounding skin for protection. The patients washed off the 25\%PSP after 4 hours of the application, and they were prescribed topical ointments with lidocaine, silver sulfadiazine, and vitamin A to apply between treatments.

Dermatitis secondary to treatment was classified as follows: erythema (mild), excoriation (moderate), asuperficial ulceration (severe).

The response rate was assessed by comparing measurements and the overall decrease in volume of the GPC based on photos from the first and last sessions.

After completing the treatment, the patients were followed up every month for six months to assess if there was any evidence of persistence or recurrence.

\section{Results}

From December 1, 2015, to December 1, 2019, 229 patients (168 men, 48 women, and 12 transgender women) with anal HPV-related lesions were evaluated and treated at our tertiary referral proctology service. In total, 126 patients were PLHIV, and their mean age was 33 (range: 16 to 72 ) years.

A total of 14 patients had GPC, and were treated with $25 \%$ PSP. - Table 1 summarizes the characteristics of the patients.

The mean age of the total sample was 34.5 (range: 16 to 68 ) years. Overall, 12 patients were immunosuppressed: 9 patients were PLHIV, 2 were transplant recipients, and 1 was on chronic corticosteroid treatment. The two immunocompetent patients were heavy smokers. The PLHIV had a mean time since HIV diagnosis of 42 months (range: 1 to 468 months), a mean CD4 count of 373 (range: 225 to 525), and 5 were undergoing antiretroviral therapy. All the perianal lesions were circumferential, and the mean longest dimension was $11 \mathrm{~cm}$ (range: $8 \mathrm{~cm}$ to $20 \mathrm{~cm}$ ). Malodorous exudate from the GPC was present in nine partients, who were treated with oral metronidazole prior to the topical treatment.

The pretreatment histology showed low squamous intraepithelial lesions in all cases.

The mean number of treatment sessions with 25\%PSP was 4.8 (range: 4 to 8 ). The sessions were weekly for 13 patients. One incarcerated patient had biweekly clinical sessions because of logistic reasons; imiquimod cream at $5 \%$ was self-applied between sessions. 


\begin{tabular}{|c|c|c|c|c|c|c|c|c|c|c|c|c|c|c|}
\hline 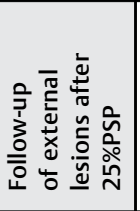 & $\begin{array}{l}\mathbf{E} \\
\text { 苋 } \\
0\end{array}$ & 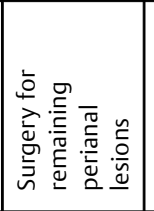 & 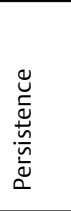 & 忌 & $\begin{array}{l}\vec{P} \\
\end{array}$ & 邑 & 芭 & 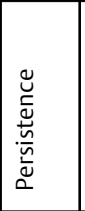 & 邑 & 芭 & 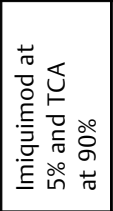 & 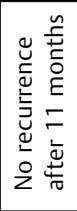 & 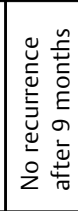 & 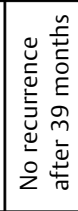 \\
\hline 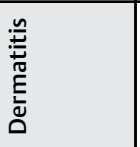 & 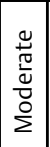 & 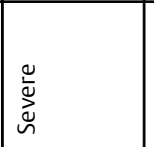 & $\frac{\bar{D}}{\overline{\bar{\Sigma}}}$ & 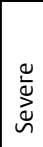 & 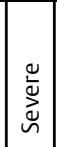 & 일 & 2 & 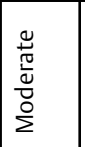 & 2 & 2o & 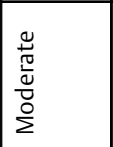 & z & z & 2 \\
\hline 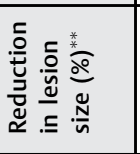 & 迟 & ㅇํํ & $\stackrel{\circ}{\circ}$ & 产 & 웃 & 웃 & ㅇํํ & ○ें & ○ें & ○े & ڤั & @े & ○ें & ○े \\
\hline 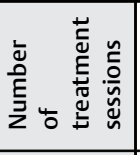 & $\nabla$ & $\nabla$ & 乞n & $\theta$ & $\nabla$ & $\nabla$ & in & $\nabla$ & $\nabla$ & in & $\nabla$ & $\wedge$ & in & $\infty$ \\
\hline $\begin{array}{l}\text { वे } \\
\frac{\circ}{0} \\
\frac{\hat{\underline{n}}}{1}\end{array}$ & $\cup$ & ż & $\bar{z}$ & $u$ & $\cup$ & $u$ & ż & 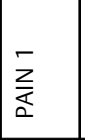 & $\bar{z}$ & $\bar{z}$ & $\frac{-}{z}$ & $\cup$ & $\bar{z}$ & $\bar{z}$ \\
\hline 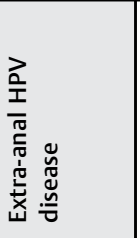 & 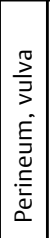 & i & 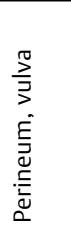 & 운 & 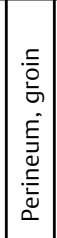 & 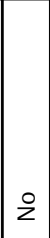 & 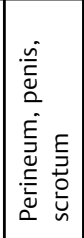 & 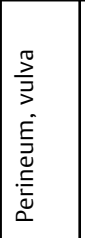 & 2 & 2 & 2 & 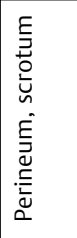 & z & 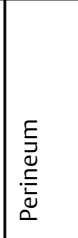 \\
\hline 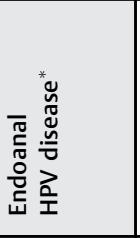 & 2 & 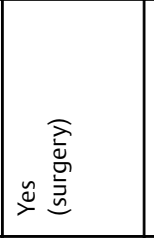 & 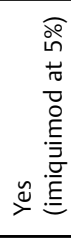 & $\stackrel{\circ}{2}$ & 2 & $\stackrel{\circ}{2}$ & 2 & 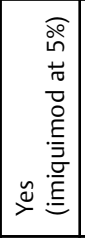 & 2 & 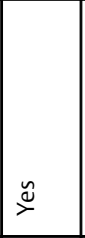 & 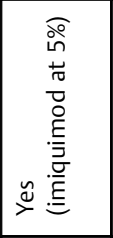 & $\stackrel{2}{2}$ & 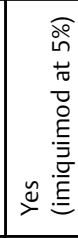 & z \\
\hline 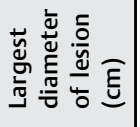 & $\infty$ & $\infty$ & $\infty$ & $\stackrel{\infty}{\square}$ & i & $\circ$ & $\stackrel{\infty}{\sim}$ & $\infty$ & $\circ$ & $\infty$ & $\infty$ & $\infty$ & $\infty$ & $\stackrel{0}{\circ}$ \\
\hline 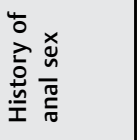 & 2 & $\stackrel{\check{\nu}}{\varnothing}$ & 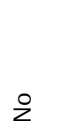 & $\frac{0}{2}$ & ₹ & $\stackrel{\check{y}}{\varnothing}$ & $2 \frac{0}{2}$ & 2 & $\stackrel{\mathscr{y}}{\succ}$ & $\stackrel{\check{y}}{\succ}$ & $\stackrel{\mathscr{y}}{\succ}$ & z & $\stackrel{\check{y}}{\rightleftharpoons}$ & 2o \\
\hline 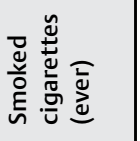 & 2 & $2 \frac{0}{2}$ & 2 & i & $\stackrel{\check{y}}{>}$ & $\stackrel{\check{y}}{\rightleftharpoons}$ & $\stackrel{\check{\varpi}}{\rightleftharpoons}$ & 2o & $\stackrel{\check{y}}{\succ}$ & 20 & 2 & $\stackrel{\check{y}}{\rightleftharpoons}$ & $\stackrel{\check{\varpi}}{\rightleftharpoons}$ & $\stackrel{\check{\nu}}{\check{0}}$ \\
\hline 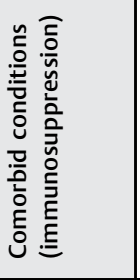 & 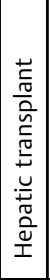 & $\underset{3}{3}$ & 主 & 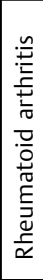 & 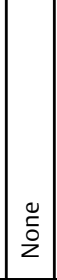 & $\mid \begin{array}{l}0 \\
\tilde{0} \\
z\end{array}$ & $\gtreqless$ & 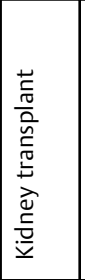 & $\geqq$ & \} $&{\text { 》) }} &{\text { 主 }} &{\text { 主 }} &{\text { 主 }} \\
{\hline \text { 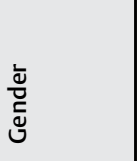 }} &{\text { 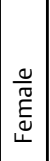 }} &{\frac{0}{2 \pi}} &{\text { 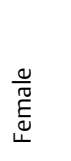 }} &{\frac{0}{\frac{0}{20}}} &{\text { 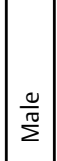 }} &{\frac{\frac{0}{N}}{\sum}} &{\frac{\frac{0}{\pi}}{2 \pi}} &{\text { 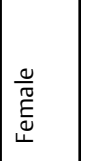 }} &{\frac{\frac{0}{N}}{\sum}} &{\text { 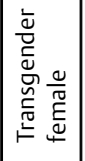 }} &{\frac{0}{\frac{0}{N \pi}}} &{\text { 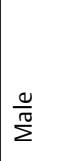 }} &{\text { 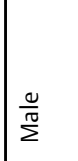 }} &{\frac{0}{\frac{0}{N \pi}}} \\
{\hline \text { 离 }} &{\div} &{\bar{\sim}} &{\stackrel{0}{\circ}} &{8} &{\infty} &{\stackrel{\sim}{\sim}} &{\bar{\gamma}} &{\text { 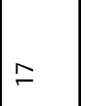 }} &{\tilde{\varphi}} &{\stackrel{\mathscr{N}}{ }} &{\ddot{\sim}} &{\bar{\tau}} &{\stackrel{\sim}{\sim}} &{\stackrel{\infty}{m}} \\
{\hline \text { 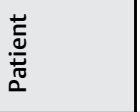 }} &{-} &{\sim} &{m} &{\sigma} &{\text { in }} &{0} &{\wedge} &{\infty} &{a} &{\stackrel{0}{\circ}} &{=} &{\simeq} &{m} &{ \pm} \\
$\hline
\end{tabular}


All patients demonstrated at least a partial response comparing measurements from the first to the last treatment visit: 10 patients had at least a $75 \%$ reduction in GPC size.

(-Figs. 1 and 2)

Dermatitis was the only side effect. It happened in seven patients (three severe cases, three moderate, one mild), and was adequately treated between sessions with an emollient.

In total, six patients did not return after four to five treatment sessions because of socioeconomic reasons. None of the three patients with complete response recurred within the follow-up period of 9 to 39 months. Two patients needed additional treatments. Two other patients had persistent disease; their underlying diseases prevented continuing the GPC treatment. The patient with a liver transplant rejected her donated organ and died of causes unrelated to the administration of $25 \%$ PSP.
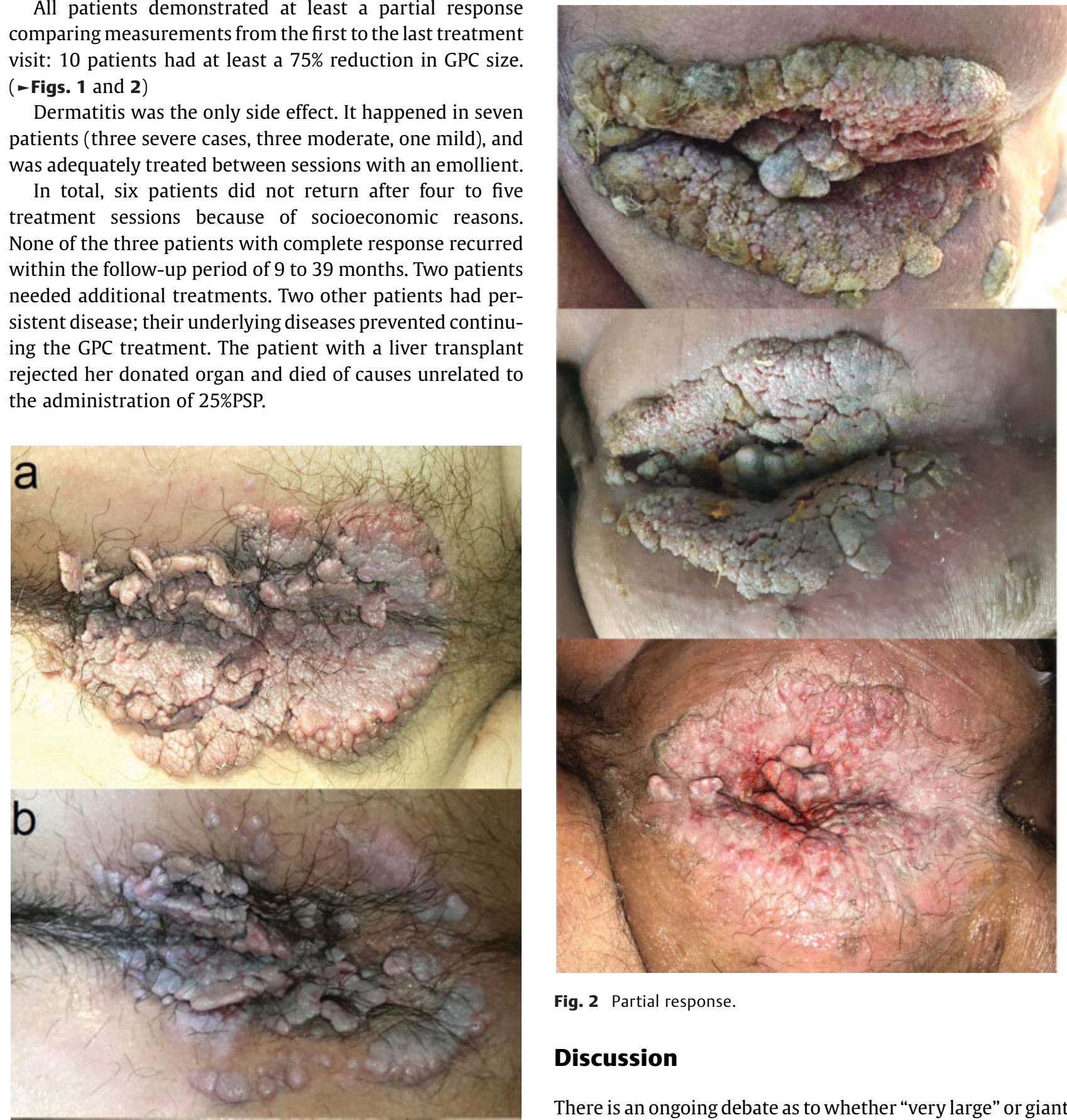

Fig. 2 Partial response.

\section{Discussion}

There is an ongoing debate as to whether "very large" or giant condyloma are the same, different, or on a continuum with Buschke Löwenstein tumor. ${ }^{1,11}$ The lack of a definition of GPC makes it difficult to determine its real incidence and to compare the results of different treatments. A review of the literature shows only case reports or small case series, ${ }^{5,12,13}$ and one of the largest series, covering the period from 1999 to 2011, reported 9 consecutive patients (6 PLHIV) with GPC (the sizes of the GPCs were not reported) treated by wide local excision and anoplasty. ${ }^{5}$

We herein report 14 cases (9 PLHIV) of GPC treated topically between 2015 and 2019. All the perianal lesions were circumferential, measuring between $8 \mathrm{~cm}$ and $20 \mathrm{~cm}$, and significantly decreased in size over the course of the treatment. The decision to include lesions of at least $8 \mathrm{~cm}$ in the present series was arbitrary; this cut-off point was 
decided since several of the largest lesions from our register had this measurement.

Surgical excision is considered the first-line approach to GPC. $^{3,5,13}$ However, surgery has the risk of side effects such as pain, wound infection, incontinence, or anal stenosis, which could interfere with quality of life and sexual function, ${ }^{4,5}$ not to mention the health care costs and the costs to the patients. Besides, the risk of recurrence after surgery is significant. ${ }^{3}$

Giant perianal condyloma is resistant to most topical therapies, especially in immunocompromised patients. Effective topical therapies would be a welcome alternative. Marino $^{12}$ reported complete response of one patient with GPC treated with imiquimod cream at $5 \%$ after 2 months, but the lesion in his report was much smaller than the ones reported in the present series.

Lacey et al. ${ }^{7}$ published a randomized, controlled multicenter trial, comparing the clinical response to podophyllotoxin cream at $0.15 \%$, podophyllotoxin solution at $0.5 \%$, and podophyllin at $25 \%$ in benzoin tincture for the treatment of condylomas (total lesions $<4 \mathrm{~cm}^{2}$ ) in 358 immunocompetent patients. Complete remission of the condyloma occurred in $75 \%, 65 \%$ and $53 \%$ of the patients treated with podophyllotoxin solution, podophyllotoxin cream, and podophyllin at $25 \%$ respectively. Only $45 \%$ of the patients with complete response returned for the post-treatment follow-up after 1 month; the recurrence rate was lower in the podophyllin arm (26\%) compared with the 2 podophyllotoxin arms ( 50\%). The volumes of the treated lesions in this study were markedly smaller compared with those in the present series.

Nadal et al. ${ }^{9}$ reported the use of 25\%PSP to treat perianal condyloma in a cohort of 67 PLHIV; $90 \%$ attained at least a partial response. Two-thirds suffered perianal burning during treatment, and one-third recurred. These results are similar to ours, but the authors did not specify the size of the lesions or the definition of partial response.

Case reports ${ }^{14,15}$ of systemic toxicity were associated with podophyllin solution applied to mucosal surfaces or friable tissue. Other articles ${ }^{7,10}$ emphasize local toxicity, particularly dermatitis, as it happened in the present series; however, this did not interfere with the scheduled treatments. The petrolatum base, which has excellent adherence to the lesions, enabled a better controlled application than the solution compounds. This may improve treatment tolerance and decrease the side effects.

Only external lesions can be treated with 25\%PSP. If the patient has endoanal disease, other treatments will be required. It is worth mentioning that in these extreme cases it may not be possible to perform an anorectal digital exam until the external lesions are treated.

Since only complete resection can assure the benignity of GPC, close follow-up to assess the response is important. If the patient does not respond to the topical treatment, or if the lesion develops suspicious characteristics, additional biopsies should be performed.

The limitations of the present study include its retrospective design, its restriction to a single center, and the incom- plete follow-up data. Its strengths are the inclusion of immunocompromised patients and the careful photodocumentation of the lesions at every visit, which demonstrated the response to the treatment.

Giant perianal condyloma is rare and difficult to treat, especially in immunocompromised patients. The present series shows that 25\%PSP is an effective and well-tolerated first-line treatment. Even if only a partial response is obtained, the treatment may simplify the subsequent treatments.

It is not easy to find several patients with GPC at one institution. To our knowledge, the present is the largest case series in the literature demonstrating the successful topical treatment of GPC. Multi-center studies should be performed to better evaluate the safety and tolerability of 25\%PSP.

Conflict of Interests

The authors have no conflict of interests to declare.

\section{Acknowledgments}

We are indebted to Ms. Silvina González Lorenzo for her assistance with the English version of the manuscript.

We are indebted to Dr. Eda Vinhaes for her assistance with the Portuguese version of the manuscript.

\section{References}

1 Trombetta LJ, Place RJ. Giant condyloma acuminatum of the anorectum: trends in epidemiology and management: report of a case and review of the literature. Dis Colon Rectum 2001;44 (12):1878-1886. Doi: 10.1007/BF02234473

2 Svidler López L, La Rosa L. Human Papilloma Virus Infection and Anal Squamous Intraepithelial Lesions. Clin Colon Rectal Surg 2019;32(05):347-357. Doi: 10.1055/s-0039-1687830

3 Gilson R, Nugent D, Werner RN, Ballesteros J, Ross J. 2019 IUSTIEurope guideline for the management of anogenital warts. J Eur Acad Dermatol Venereol 2020;34(08):1644-1653. Doi: 10.1111/ jdv.16522

4 Orkin BA. Perineal reconstruction with local flaps: technique and results. Tech Coloproctol 2013;17(06):663-670. Doi: 10.1007/ s10151-013-0978-y

5 Uribe N, Rueda C, López M, et al. Management of giant anal condyloma by wide local excision and anoplasty. Colorectal Dis 2012;14(11):1394-1397. Doi: 10.1111/j.1463-1318.2012.03006.x

6 Paddock Laboratories, LLC. PODOCON 25- podophyllum resin tincture. Accessed June 26, 2020 at: https://dailymed.nlm.nih.gov/dailymed/fda/fdaDrugXsl.cfm?setid=de96dc6ee6d1-43839ce1-4d06bac08e00\&type=display

7 Lacey CJN, Goodall RL, Tennvall GR, et al; Perstop Pharma Genital Warts Clinical Trial Group. Randomised controlled trial and economic evaluation of podophyllotoxin solution, podophyllotoxin cream, and podophyllin in the treatment of genital warts. Sex Transm Infect 2003;79(04):270-275. Doi: 10.1136/sti.79.4.270

8 von Krogh G, Longstaff E. Podophyllin office therapy against condyloma should be abandoned. Sex Transm Infect 2001;77 (06):409-412. Doi: 10.1136/sti.77.6.409

9 Nadal SR, Manzione CR, Couto Horta SH, De Moura Galvao V. Tratamento Tópico dos condilomas acuminados perianais em doentes HIV. Rev Bras Coloproctol 1999;19(02):79-82

10 Nadal SR, Manzione CR, Horta SHC, Calore EE. Sistematização do atendimento dos portadores de infeccão perianal pelo papilomavirus humano (HPV). Rev Bras Coloproctol 2004;24(04):322-328 
https://pdfs.semanticscholar.org/4069/7041fae8c45dc6c6302 cf6a0f158c11ea3a2.pdf

11 Abbass MA, Valente MA. Premalignant and Malignant Perianal Lesions. Clin Colon Rectal Surg 2019;32(05):386-393. Doi: 10.1055/s-0039-1687835

12 Marino F. Complete healing of perianal giant condyloma (buschke-löwenstein tumor) with imiquimod 5\% cream alone. [published online ahead of print, 2020 Jun 30]Tech Coloproctol 2020;24(12):1313-1314. Doi: 10.1007/s10151-02002280-Z
13 Guttadauro A, Chiarelli M, Macchini D, et al. Circumferential anal giant condyloma acuminatum: a new surgical approach. Dis Colon Rectum 2015;58(04):e49-e52. Doi: 10.1097/DCR.0000000000000339

14 Filley CM, Graff-Richard NR, Lacy JR, Heitner MA, Earnest MP. Neurologic manifestations of podophyllin toxicity. Neurology 1982;32(03):308-311. Doi: 10.1212/wnl.32.3.308

15 Conard PF, Hanna N, Rosenblum M, Gross JB. Delayed recognition of podophyllum toxicity in a patient receiving epidural morphine. Anesth Analg 1990;71(02):191-193. Doi: 10.1213/00000539199008000-00013 